\title{
Development of a fast EoS based compositional model for three-phase core flooding
}

\author{
Seyyed Ehsan Mostafavi ${ }^{1} \cdot$ Elnaz Khodapanah $^{1}$ [D $\cdot$ Seyyed Alireza Tabatabaei-Nezhad ${ }^{1}$
}

Received: 24 September 2019 / Accepted: 3 December 2019 / Published online: 7 December 2019

(c) Springer Nature Switzerland AG 2019

\begin{abstract}
Compositional simulators are of great importance to model core flow experiments and enhanced oil recovery processes. In the present study, a semi-implicit, three dimensional EoS-based formulation is developed for modeling and simulation of core-flooding process. The model treats three-phase flow in cylindrical coordinates with no need to use an iterative numerical method. Overall composition, pressure and water saturation are calculated implicitly for each grid block. Using this approach, a linear set of equations with constant coefficients would be solved at each time step. It is assumed that there is no mass transfer between hydrocarbon phases and water phase. In addition, a new technique has been suggested to calculate transmissibility coefficients in each direction, which is a major problem in compositional modeling. Each transmissibility coefficient is divided into two general parts which are treated differently. The first part is constant and the second part is time-dependent. This model yields a robust and fast calculation procedure, which is validated using Eclipse simulation results. Simulation of several miscible flooding processes were performed using Eclipse coreflood models in order to compare the results with the developed in-house model. Results are matched reasonably while the computing time is considerably decreased using the in-house model. It is shown that using second Stone's relative permeability model and Advanced Peng-Robinson Equation of State, best results are achieved with an average absolute relative deviation of $7.7 \%$ from Eclipse results for ultimate recovery factor. In addition, sensitivity analysis has been performed on several input data including time-step size and block number. Results show that in a reasonable range of these parameters, convergence problems are not encountered. We have developed an in-house simulator based on our model, which can be a basis for other compositional simulation purposes. In addition to decreasing computing time, convergence problems encountered in most implicit techniques would be avoided as well.
\end{abstract}

Keywords Compositional model · Coreflooding · Gas injection · PC-SAFT EoS · Semi-implicit · Transmissibility coefficient

\section{List of symbols}

$A_{r} \quad$ Cross-sectional area normal to $r$ direction

$A_{z} \quad$ Cross-sectional area normal to $z$ direction

$A_{\theta} \quad$ Cross-sectional area normal to $\theta$ direction

$\mathrm{H}$ Height

$k_{r g} \quad$ Relative permeability to gas phase

$k_{\text {ro }} \quad$ Relative permeability to oil phase

$k_{\text {rog }}$ Relative permeability to oil phase in two-phase oil-gas system $k_{\text {row }}$ Relative permeability to oil phase in two-phase oil-water system

$k_{r w} \quad$ Relative permeability to water phase

$K_{r} \quad$ Permeability in the direction of the $r$-axis

$K_{z} \quad$ Permeability in the direction of the $z$-axis

$K_{\theta} \quad$ Permeability in the direction of the $\theta$-axis

$n \quad$ Old time level

$n_{c} \quad$ Number of components

$N_{b} \quad$ Number of gridblocks

$P \quad$ Pressure

Elnaz Khodapanah, khodapanah@sut.ac.ir; ekhodapanah@yahoo.com | ${ }^{1}$ Faculty of Petroleum and Natural Gas Engineering, Sahand Oil and Gas Research Institute, Sahand University of Technology, Sahand New City, Tabriz 5331817634, Iran. 
$P_{\text {cgo }} \quad$ Gas-oil capillary pressure

$P_{\text {cwo }}$ Water-oil capillary pressure

$S_{g} \quad$ Saturation of gas phase

$S_{0} \quad$ Saturation of oil phase

$S_{w} \quad$ Saturation of water phase

$t \quad$ Time

T Transmissibility

$\checkmark \quad$ Bulk volume, control volume or gridblock bulk volume

$x_{i} \quad$ Mole fraction of component $i$ in oil phase

$y_{i} \quad$ Mole fraction of component $i$ in gas phase

$z_{i} \quad$ Overall composition of component $i$

$Z \quad$ Elevation

$\gamma_{g} \quad$ Gravity of the gas phase

$\gamma_{o} \quad$ Gravity of the oil phase

$\gamma_{w} \quad$ Gravity of the water phase

$\bar{\delta} \quad$ Difference operator in the time domain

$\Delta \quad$ Central difference operator in the spatial domain

$\Delta \mathrm{t} \quad$ Time step

$\theta$ Angle in the $\theta$ direction in cylindrical coordinate system

$\mu_{g} \quad$ Gas-phase viscosity

$\mu_{o} \quad$ Oil-phase viscosity

$\mu_{w} \quad$ Water-phase viscosity

$\rho_{g} \quad$ Gas-phase density

$\rho_{0} \quad$ Oil-phase density

$\rho_{w} \quad$ Water-phase density

$\phi \quad$ Porosity

\section{Introduction}

"Black-oil" modeling allows an assumption that reservoir gas and oil have different but fixed composition, with the solubility of gas in oil being dependent on pressure alone. In "compositional" models, oil and gas equilibrium compositions vary considerably with spatial position and time [1].

Van Quy et al. [2] developed a compositional model describing a one-dimensional, two-phase (gas/oil) system, neglecting capillary and gravity forces. A three-component correlation was used which guaranteed consistency of phase compositions and properties at the critical point. Corteville et al. [3] presented additional comparisons between experimental and linear calculated results using the same model.

Metcalfe et al. [4] and Fussel et al. [5] published researches in order to simulate the multi-contact miscibility process using a cell-to-cell flash calculation model. Iterative methods were described by Fussell and Yanosik [6] for phase equilibria calculations using Redlich-Kwong equation of state. Fussel and Fussel [7] developed a formulation for a multidimensional compositional model. They used their model for an immiscible gas injection case, as an example.

Coats [1] described an equation-of-state implicit compositional model formulation for three-dimensional, threephase flow under viscous, gravity and capillary forces. In his formulation, $2 \mathrm{~N}_{\mathrm{c}}+4$ equations should be solved simultaneously, using an iterative procedure which makes the calculations time-consuming.

Although fully-implicit approach is an accurate method, it has some drawbacks including numerical dispersion and lower computational speed. IMPES model was presented in 1981 by Nghiem et al. [8] which solves a set of equations using an iterative-sequential method. Implicit formulation for pressure equation which results from combination of mass balance equation for water phase and molar balance for hydrocarbon system, would be solved using a direct method or Newton-like iterative procedure. After calculating pressures in each iteration step, water saturation and overall molar hydrocarbon composition would be calculated explicitly. Flash calculations are performed to find molar composition, density and mole fraction of each phase. Then saturation of each hydrocarbon phase could be calculated. The main drawback of this formulation is limitation on time step length which is related to explicit solving for composition and transmissibility parameter. Young and Stephenson [9] suggested a more efficient procedure on the basis of Newton-Raphson method to solve IMPES equations.

Branco and Rodrigues [10] developed a semi-implicit model for compositional simulation where mole fractions of components in mass balance equations are calculated explicitly one step earlier than each iteration. Equations would be divided into two sets. One of them including three equations with three unknowns like black-oil equations and the other one including $\mathrm{N}_{\mathrm{c}}-2$ equations for mole fraction of components in one phase. The level of implicitness of this method is something between IMPES and fully implicit methods.

In 2011, Wei et al. applied APR EoS in Coats method and presented a new algorithm for multiphase flash calculations. They used Michelsen stability analysis in their model [11].

In 2013, Zaydullin et al. presented a new framework for the general compositional problem associated with multicomponent multiphase flow in porous media. Adaptive construction and interpolation using supporting tie lines were used in their model to obtain the phase state and the phase compositions. The computation of the phase behavior in the course of simulations becomes an iteration-free, table look-up procedure [12].

In 2015, Fleming developed a method to locally lump the fluid for phase-behavior calculations. In his method, the regions that are able to maintain sufficient 
compositional accuracy with fewer components can use less-expensive EoS calculations. In addition, different lumpings can be used at different times in the life of the reservoir, as compositional effects become more or less important in different regions in the reservoir [13].

In 2018, Khorsandi et al. developed a fully compositional simulation model using an equation of state (EoS) for relative permeabilities to eliminate the unphysical discontinuities in flux functions caused by phase labeling. The hysteresis effects were also considered in their threephase relative permeability model. They used their mode for simulation of multi-cycle WAG injection [14].

The purpose of this research is to develop a three-phase, three-dimensional, compositional model in cylindrical coordinate system to simulate core-flooding process. An Inhouse simulator has been developed based on the proposed model, which is used to obtain results, validate and analyze the model.

\section{Description of the model}

The main features of our model include:

- Three-phase including oil, gas and water

- Three-dimensional, cylindrical, in vertical or horizontal directions

- Compositional

- Describing phase behavior using equations of state

The proposed model is based on finite difference method of discretization, originally suggested by Coats [1], associated with minor modifications. Since flash calculations using an equation of state is performed at each time step for each grid block, the computation is naturally time-consuming. The main focus of this research is on the method of discretization of the flow equations, and on proper selection of the parameters that are going to be solved implicitly/ explicitly. In most previous researches, the discretization method of the flow equations results in a set of equations with multiple unknown parameters. These equations are then combined into a single matrix equation. If the final multiplier matrix of the unknown parameters contains unknowns itself, the equation is to be solved using iterative numerical methods. However, it has been tried in the proposed method to reach a multiplier matrix of constant values, at each time step. It should be noted that the multiplier matrix of constant values changes at each time step and is not constant throughout the whole simulation.
The suggested discretization method of the flow equations for each block is represented hereunder. The $\mathrm{N}_{\mathrm{c}} \mathrm{com}$ ponent mass balances are:

$$
\begin{aligned}
\frac{V}{\Delta t} \bar{\delta} & {\left[\phi\left(\rho_{o} S_{o} x_{i}+\rho_{g} S_{g} y_{i}\right)\right] } \\
= & \Delta\left[T \rho_{o} x_{i} \frac{k_{r o}}{\mu_{o}}\left(\Delta p-\Delta P_{c g o}-\gamma_{o} \Delta Z\right)\right] \\
& +\Delta\left[T \rho_{g} y_{i} \frac{k_{r g}}{\mu_{g}}\left(\Delta p-\gamma_{g} \Delta Z\right)\right]-q_{i} \quad i=1,2, \ldots, N_{c}
\end{aligned}
$$

The water mass balance is:

$\frac{V}{\Delta t} \bar{\delta}\left[\phi\left(\rho_{w} S_{w}\right)\right]=\Delta\left[T \rho_{w} \frac{k_{r w}}{\mu_{w}}\left(\Delta p-\Delta P_{c g o}-\Delta P_{c w o}-\gamma_{w} \Delta Z\right)\right]$

where $\bar{\delta}$ and $\Delta$ are the difference operators, defined as the following:

$\bar{\delta} X=X^{n+1}-X^{n}$

$\Delta(T \Delta X)=\Delta_{r}\left(T_{r} \Delta_{r} X\right)+\Delta_{\theta}\left(T_{\theta} \Delta_{\theta} X\right)+\Delta_{z}\left(T_{z} \Delta_{z} X\right)$

$\Delta_{X}\left(T_{x} \Delta_{X} X\right)=T_{x, i+\frac{1}{2}}\left(X_{i+1}-X_{i}\right)+T_{x, i-\frac{1}{2}}\left(X_{i-1}-X_{i}\right)$

The left-hand side of Eq. 1 can be written as:

$\frac{V}{\Delta t}\left(\left[\phi z_{i}\left(\rho_{o} S_{o}+\rho_{g} S_{g}\right)\right]^{n+1}-\left[\phi z_{i}\left(\rho_{o} S_{o}+\rho_{g} S_{g}\right)\right]^{n}\right)$

The assumptions of the proposed model include:

- Capillary pressure is neglected

- No mass transfer occurs between water and hydrocarbon phases

- Variables that are calculated implicitly are: $p, S_{w^{\prime}} z_{1}, z_{2^{\prime}}$ $\ldots, z_{n_{c}}$

- Transmissibility coefficients are assumed to be the product of two parameters, $T$ and $W$, multiplied by each other. $T$ does not change as time proceeds, while $W$ is dependent on time. They are defined as the following:

$$
\begin{aligned}
& T_{r, i \pm \frac{1}{2} j, k}=\left.\beta_{c} K_{r} \frac{A_{r}}{\Delta r}\right|_{i \pm \frac{1}{2}} \\
& T_{\theta, i, j \pm \frac{1}{2}, k}=\left.\beta_{c} \frac{K_{\theta} A_{\theta}}{r_{i j k} \Delta \theta}\right|_{j \pm \frac{1}{2}}
\end{aligned}
$$




$$
\begin{aligned}
& T_{z, i, j, k \pm \frac{1}{2}}=\left.\beta_{c} \frac{K_{z} A_{z}}{\Delta z}\right|_{k \pm \frac{1}{2}} \\
& W_{o, a, i, j, k}=\left(\rho_{o} x_{a} \frac{k_{r o}}{\mu_{o}}\right)_{i, j, k} \\
& W_{g, a, i, j, k}=\left(\rho_{g} y_{a} \frac{k_{r g}}{\mu_{g}}\right)_{i, j, k}
\end{aligned}
$$

$$
\begin{aligned}
& \frac{V}{\Delta t} \phi\left(\rho_{o} S_{o}+\rho_{g} S_{g}\right)\left[z_{i}\right]_{n+1} \\
& +p_{i, j, k}\left(T_{z, i}\left(W_{o, k-\frac{1}{2}}+W_{o, k+\frac{1}{2}}+W_{g, k-\frac{1}{2}}+W_{g, k+\frac{1}{2}}\right)\right. \\
& +T_{\theta, i}\left(W_{o, j-\frac{1}{2}}+W_{o, j+\frac{1}{2}}+W_{g, j-\frac{1}{2}}+W_{g, j+\frac{1}{2}}\right)+T_{r, i-\frac{1}{2}}\left(W_{o, i-\frac{1}{2}}+W_{g, i-\frac{1}{2}}\right) \\
& \left.+T_{r, i+\frac{1}{2}}\left(W_{o, i+\frac{1}{2}}+W_{g, i+\frac{1}{2}}\right)\right)+p_{i, j, k-1}\left(-T_{z, i}\left(W_{o, k-\frac{1}{2}}+W_{g, k-\frac{1}{2}}\right)\right) \\
& +p_{i, j-1, k}\left(-T_{\theta, i}\left(W_{o, j-\frac{1}{2}}+W_{g, j-\frac{1}{2}}\right)\right) \\
& +p_{i-1, j, k}\left(-T_{r, i-\frac{1}{2}}\left(W_{o, i-\frac{1}{2}}+W_{g, i-\frac{1}{2}}\right)\right) \\
& +p_{i+1, j, k}\left(-T_{r, i+\frac{1}{2}}\left(W_{o, i+\frac{1}{2}}+W_{g, i+\frac{1}{2}}\right)\right) \\
& +p_{i, j+1, k}\left(-T_{\theta, i}\left(W_{o, j+\frac{1}{2}}+W_{g, j+\frac{1}{2}}\right)\right) \\
& +p_{i, j, k+1}\left(-T_{z, i}\left(W_{o, k+\frac{1}{2}}+W_{g, k+\frac{1}{2}}\right)\right) \\
& =\frac{V}{\Delta t}\left[z_{i} \phi\left(\rho_{o} S_{o}+\rho_{g} S_{g}\right)\right]_{n}-q_{i} \\
& +H_{i, j, k}\left(T _ { z , i } \left(W_{o, k-\frac{1}{2}} \gamma_{o, k-\frac{1}{2}}+W_{o, k+\frac{1}{2}} \gamma_{o, k+\frac{1}{2}}+W_{g, k-\frac{1}{2}} \gamma_{g, k-\frac{1}{2}}\right.\right. \\
& \left.+W_{g, k+\frac{1}{2}} \gamma_{g, k+\frac{1}{2}}\right) \\
& +T_{\theta, i}\left(W_{o, j-\frac{1}{2}} \gamma_{o, j-\frac{1}{2}}+W_{o, j+\frac{1}{2}} \gamma_{o, j+\frac{1}{2}}+W_{g, j-\frac{1}{2}} \gamma_{g, j-\frac{1}{2}}+W_{g, j+\frac{1}{2}} \gamma_{g, j-\frac{1}{2}}\right) \\
& +T_{r, i-\frac{1}{2}}\left(W_{o, i-\frac{1}{2}} \gamma_{o, i-\frac{1}{2}}+W_{g, i-\frac{1}{2}} \gamma_{g, i-\frac{1}{2}}\right)+T_{r, i+\frac{1}{2}}\left(W_{o, i+\frac{1}{2}} \gamma_{o, i+\frac{1}{2}}\right. \\
& \left.\left.+W_{g, i+\frac{1}{2}} \gamma_{g, i+\frac{1}{2}}\right)\right)+H_{i, j, k-1}\left(-T_{z, i}\left(W_{o, k-\frac{1}{2}} \gamma_{o, k-\frac{1}{2}}+W_{g, k-\frac{1}{2}} \gamma_{g, k-\frac{1}{2}}\right)\right) \\
& +H_{i, j-1, k}\left(-T_{\theta, i}\left(W_{o, j-\frac{1}{2}} \gamma_{o, j-\frac{1}{2}}+W_{g, j-\frac{1}{2}} \gamma_{g, j-\frac{1}{2}}\right)\right) \\
& +H_{i-1, j, k}\left(-T_{r, i-\frac{1}{2}}\left(W_{o, i-\frac{1}{2}} \gamma_{0, i-\frac{1}{2}}+W_{g, i-\frac{1}{2}} \gamma_{g, i-\frac{1}{2}}\right)\right) \\
& +H_{i+1, j, k}\left(-T_{r, i+\frac{1}{2}}\left(W_{o, i+\frac{1}{2}} \gamma_{o, i+\frac{1}{2}}+W_{g, i+\frac{1}{2}} \gamma_{g, i+\frac{1}{2}}\right)\right) \\
& +H_{i, j+1, k}\left(-T_{\theta, i}\left(W_{o, j+\frac{1}{2}} \gamma_{o, j+\frac{1}{2}}+W_{g, j+\frac{1}{2}} \gamma_{g, j+\frac{1}{2}}\right)\right) \\
& +H_{i, j, k+1}\left(-T_{z, i}\left(W_{o, k+\frac{1}{2}} \gamma_{o, k+\frac{1}{2}}+W_{g, k+\frac{1}{2}} \gamma_{g, k+\frac{1}{2}}\right)\right)
\end{aligned}
$$


Table 1 Hypothetical corefluid composition

\begin{tabular}{ll}
\hline Component & $\begin{array}{l}\text { Compo- } \\
\text { sition } \\
\text { (mol\%) }\end{array}$ \\
\hline$C_{1}$ & 10 \\
$C_{5}$ & 10 \\
$C_{10}$ & 10 \\
$C_{15}$ & 10 \\
$C_{33}$ & 60 \\
\hline
\end{tabular}

Therefore, $N_{c}$ flow equations for hydrocarbon and nonhydrocarbon components, a water flow equation and a limiting equation on the summation of overall compositions (Eq. 14) exist for each grid block, that would be $N_{c}+2$ equations.

$\sum_{i=1}^{n_{c}} z_{i}=1$

The number of implicitly estimated unknowns for each gridblock would be $N_{c}+2$ as well. Hence, if $N_{b}$ represents the number of grid blocks, $N_{b} \times\left(N_{c}+2\right)$ equations should be solved simultaneously. The main feature of this formulation is that the set of equations is linear, i.e., the multiplier matrix components are constant at each timestep. This feature reduces computational time considerably.

After determining unknowns in each gridblock, flash calculation is performed using an equation of state. We have applied APR and PC-SAFT equations of state in the proposed model. Three viscosity models have been applied to the developed simulator; LBC (LohrenzBray-Clark) [15], modified LBC [16] and EF Correlation (Expanded Fluid) by Satyro and Yarranton [17] considering a modification in mixing rules, suggested by Motahhari [18].

Four relative permeability models have been applied; the first and the second Stone's models [19, 20], Naar, Henderson and Wygal $[21,22]$ and Corey's relative permeability models [23].

Eight user-defined multipliers have been introduced to find the optimum way of treating inter-blocks transmissibility parameters; $g_{1}, g_{2}, g_{3}, g_{4}, I_{1}, I_{2}, l_{3}, I_{4}$. Four adjacent blocks are selected in the flow direction such that, $g_{i}$ and $I_{i}$ would be multiplied by $W_{g}$ and $W_{o}$ of the respective blocks, assuming fluid flow between block numbers 2 and 3. These multipliers have been optimized and reported in results section.

The in-house simulator has been developed in Visual C\# with a user-friendly interface. It is specially developed for core-flooding process, though it can be generalized to other processes occurring in reservoir scale.
Table 2 Input data of the validation model

\begin{tabular}{lcl}
\hline Property & Quantity & Unit \\
\hline Core length & 34.56 & $\mathrm{~cm}$ \\
Core diameter & 2.376 & $\mathrm{~cm}$ \\
Porosity & 33.57 & $\%$ \\
Absolute permeability & 45.23 & $\mathrm{md}$ \\
Water saturation & 29.44 & $\%$ \\
Irreducible water saturation & 29.44 & $\%$ \\
Injection rate & 0.10 & $\mathrm{cc} / \mathrm{min}$ \\
\hline
\end{tabular}

Table 3 Models used in validation

\begin{tabular}{|c|c|}
\hline Viscosity model & $\begin{array}{l}\text { LBC } \\
\quad \text { (Lohrenz- } \\
\text { Bray- } \\
\text { Clark) }\end{array}$ \\
\hline EoS & $\begin{array}{l}\text { APR } \\
\text { (Advanced } \\
\text { Peng- } \\
\text { Robinson) }\end{array}$ \\
\hline $\begin{array}{l}\text { Relative perme- } \\
\text { ability model }\end{array}$ & Stone 2 \\
\hline
\end{tabular}

Table 4 Gridblocks numbers in different axis of the horizontal and vertical model

\begin{tabular}{lllc}
\hline Simulator & Flow direction & $\begin{array}{l}\text { Coordinate } \\
\text { direction }\end{array}$ & $\begin{array}{l}\text { Blocks } \\
\text { num- } \\
\text { ber }\end{array}$ \\
\hline Eclipse & Vertical (cylindrical) & $r$ & 5 \\
& & $\theta$ & 5 \\
& Horizontal (Cartesian, & $x$ & 10 \\
& eight-points) & $y$ & 5 \\
In-house simulator & Vertical (cylindrical) & $r$ & 5 \\
& & $\theta$ & 20 \\
& & $z$ & 4 \\
& & $r$ & 6 \\
& Horizontal (cylindrical) & $r$ & 4 \\
& & $\theta$ & 6 \\
& & $z$ & 20
\end{tabular}

\section{Model validation}

The developed in-house simulator has been validated in comparison with Eclipse models. Six cases of semi-miscible gas injection simulation have been performed; three of them in horizontal and the others in vertical direction. Input data to relative permeability models have been changed in each three cases. The composition of the hypothetical fluid inside the core is shown in Table 1. 


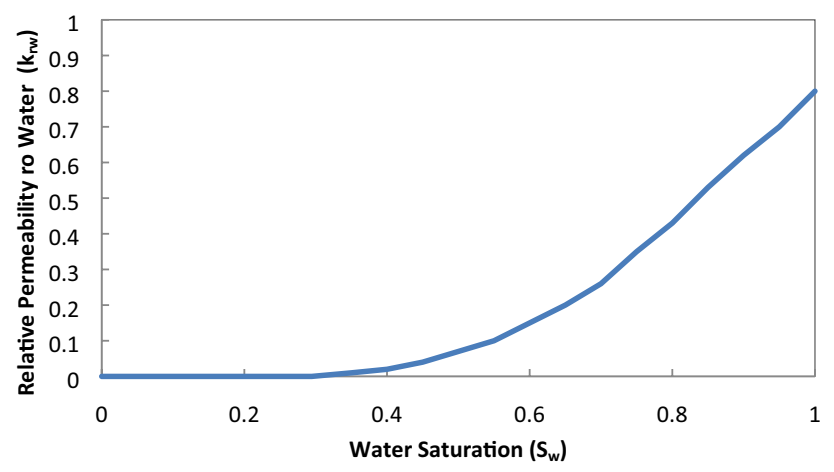

Fig. 1 Water relative permeability for Scenario\#1

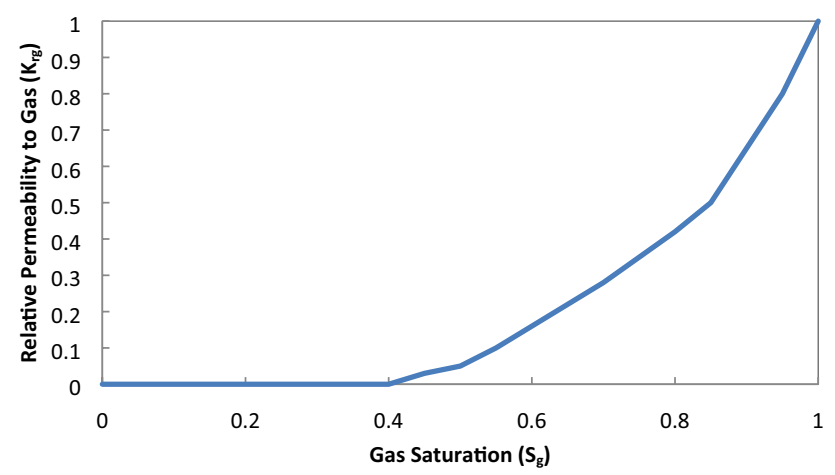

Fig. 2 Gas relative permeability for Scenario\#1

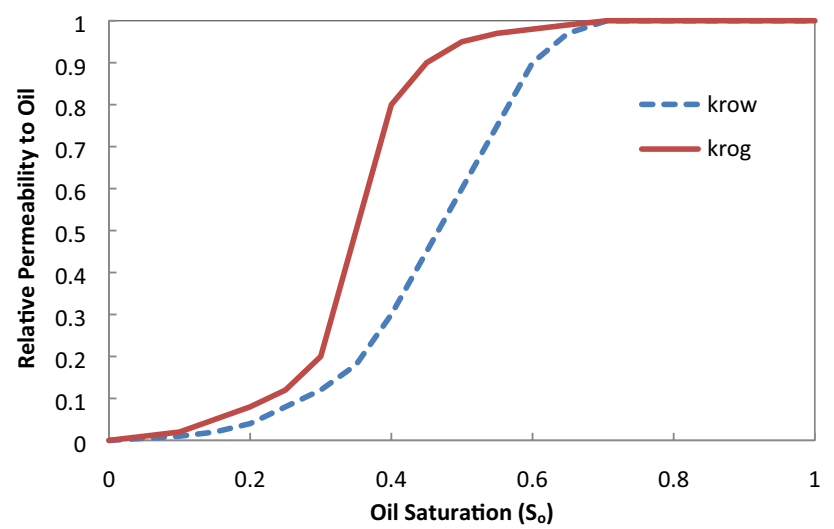

Fig. 3 Oil-water and Oil-Gas relative permeabilities for Scenario\#1

Methane has been injected at 3800 psia and temperature was held constant at $87.8^{\circ} \mathrm{C}$. Other fixed parameters in six cases of simulation are given in Table 2 . Model used to perform viscosity, relative permeability and flash calculations are given in Table 3.

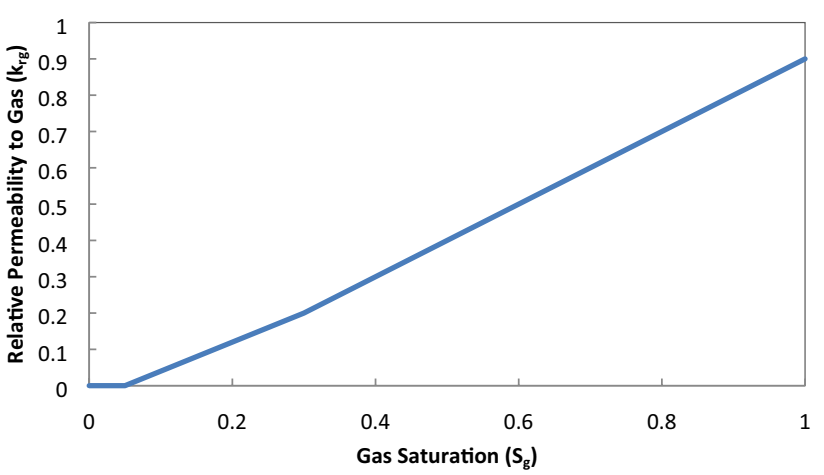

Fig. 4 Gas relative permeability FOR Scenario\#2

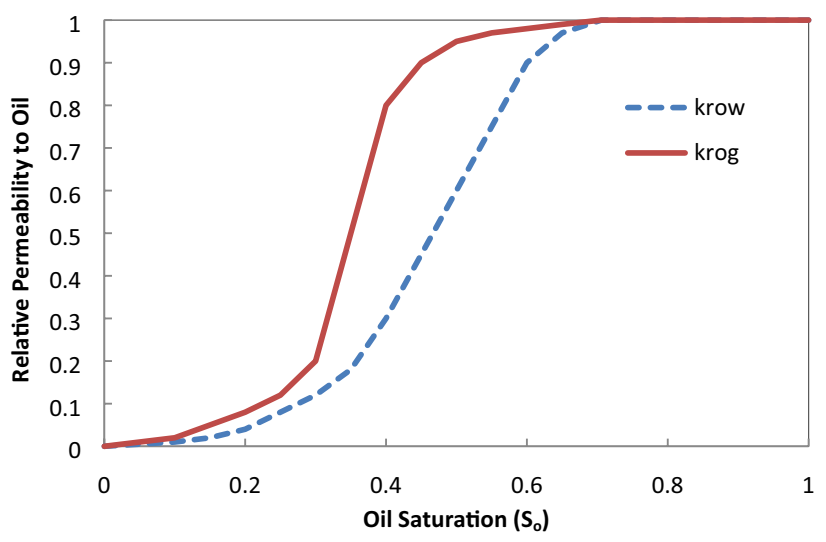

Fig. 5 Oil-water and oil-gas relative permeabilities for Scenario\#2

The second Stone's relative permeability model needs four sets of data including $k_{r w}, k_{r g}, k_{\text {rog }}$ and $k_{\text {row }}$. Three scenarios have been assumed as input data sets of the second Stone's relative permeability model. In these scenarios, $k_{r w}$ has been assumed to be constant, since the main goal of this research is to model gas injection, which is not considerably affected by water phase movement.

It should be noted that in the horizontal case, Eclipse model has been developed in eight-point Cartesian coordinates, since it is not possible to use cylindrical coordinates in horizontal direction, while the main axis of the cylinder is lateral, in this software. Table 4 represents gridblock properties applied in both software programs.

The simulation time for horizontal cases is $900 \mathrm{~s}$ and for vertical cases is 2000 s.

\subsection{Scenario \#1}

In this case, conditions of a water-wet system have been planned. Critical gas saturation is 0.4 . Figures 1,2 and 3 


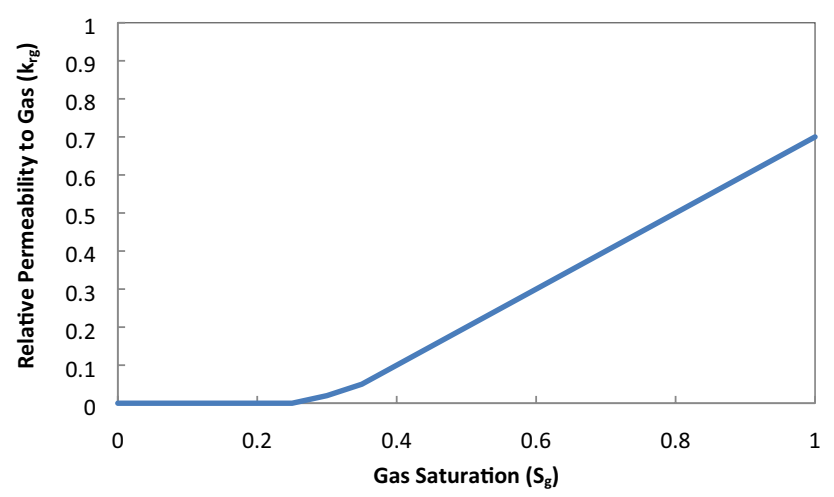

Fig. 6 Gas relative permeability for Scenario\#3

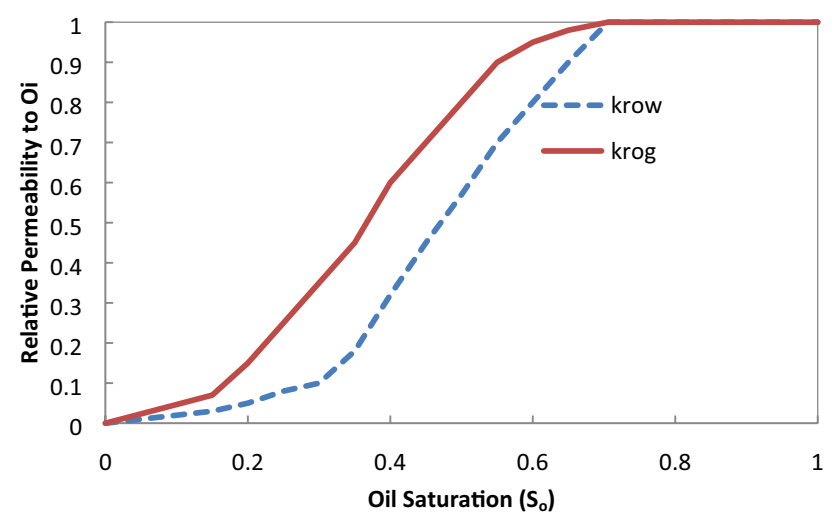

Fig. 7 Oil-water and oil-gas relative permeabilities for Scenario\#3 represent hypothetical input data of the second Stone's relative permeability model.

\subsection{Scenario \#2}

Relative permeability to water is the same as the previous case. Critical gas saturation is assumed to be 0.05 . Figures 4 and 5 represent hypothetical input data of the second Stone's relative permeability model for Scenario 2 .

\subsection{Scenario \#3}

In this case, $k_{r w}$ is the same as the other scenarios and the critical gas saturation is assumed to be 0.25 . Figures 6 and 7 depict hypothetical input data of the second Stone's relative permeability model for Scenario 3.

\section{Results}

Figures 8 through 13 depict "recovery" versus "time" on the primary horizontal axis and "PV Injected" on the secondary horizontal axis for different scenarios.

- Horizontal Case

See Figs. 8, 9 and 10.

- Vertical Case

See Figs. 11, 12 and 13.

\section{Semi-miscible displacement scenario}

During semi-miscible displacement scenario, both miscible and immiscible displacements happen. Therefore, this case could be considered as a general case. We have designed the validation problem in horizontal direction in such a way that it falls into a semi-miscible region to observe both miscible and immiscible cases at the same time.

In this section, we look closer into what happens in two blocks, the highest and the lowest blocks in a certain layer, as is shown in Fig. 14.
Fig. 8 Recovery versus time/ PV injected, horizontal case, Scenario\# 1

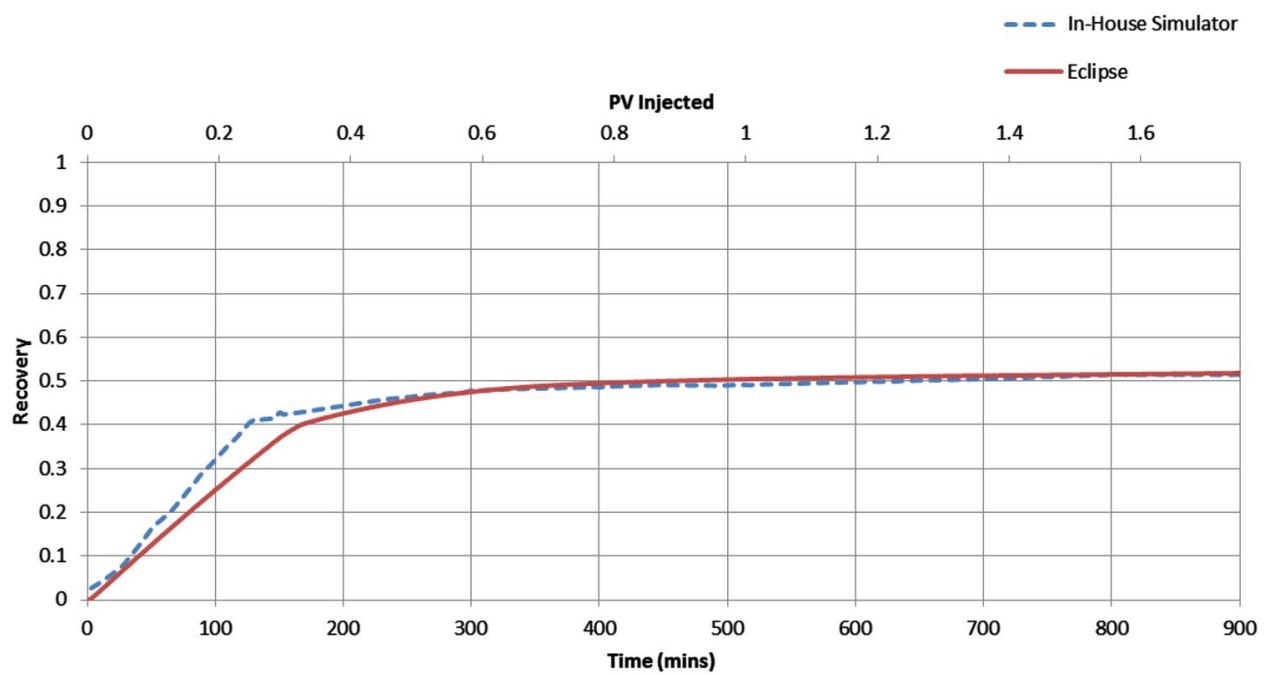

SN Applied Sciences 
Fig. 9 Recovery versus time/ PV injected, horizontal case, Scenario\#2

Fig. 10 Recovery versus time/ PV injected, horizontal case, Scenario\#3

Fig. 11 Recovery versus time/ PV injected, vertical case, Scenario\#1
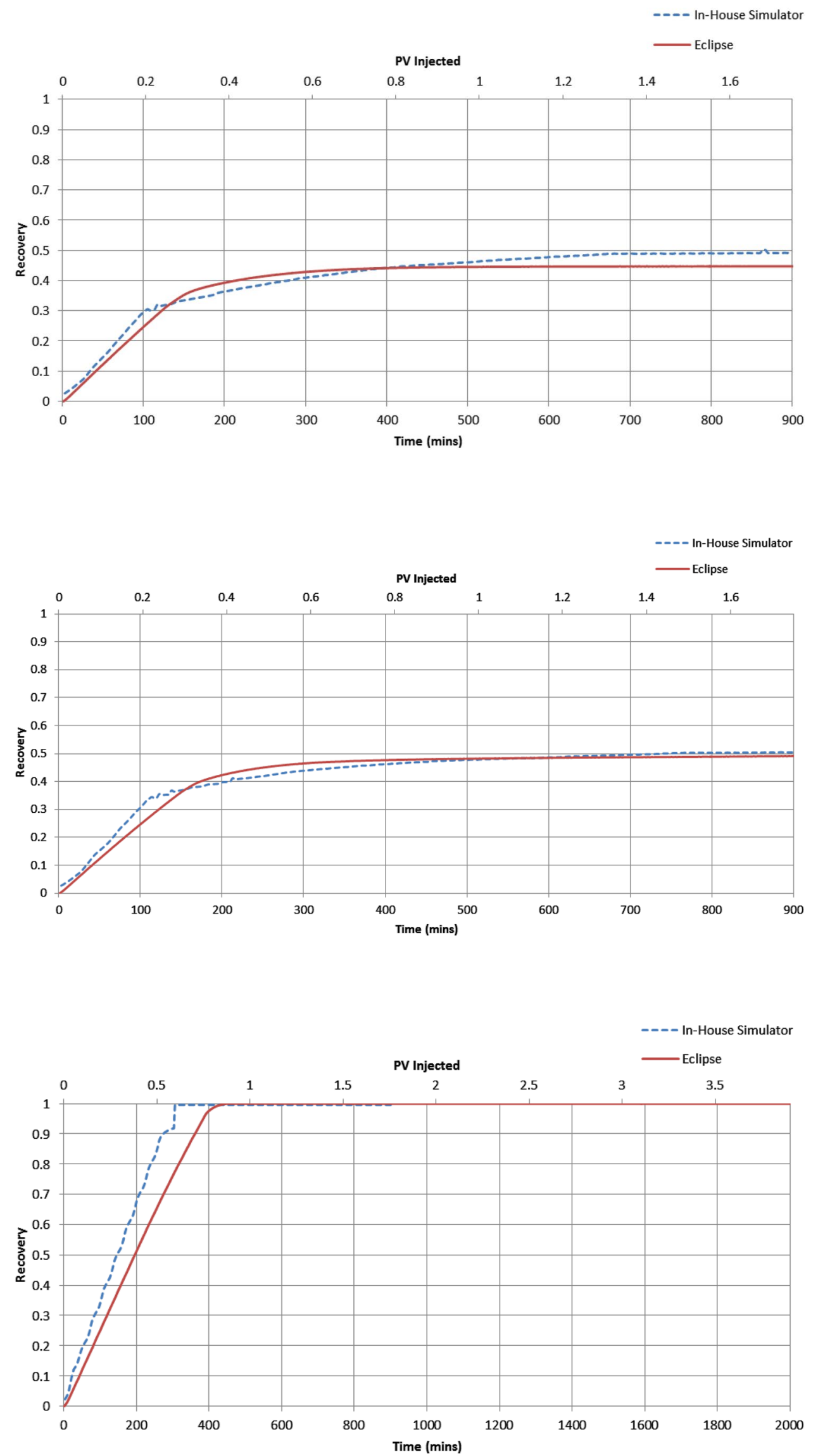
Fig. 12 Recovery versus time/ PV injected, vertical case, Scenario\#2
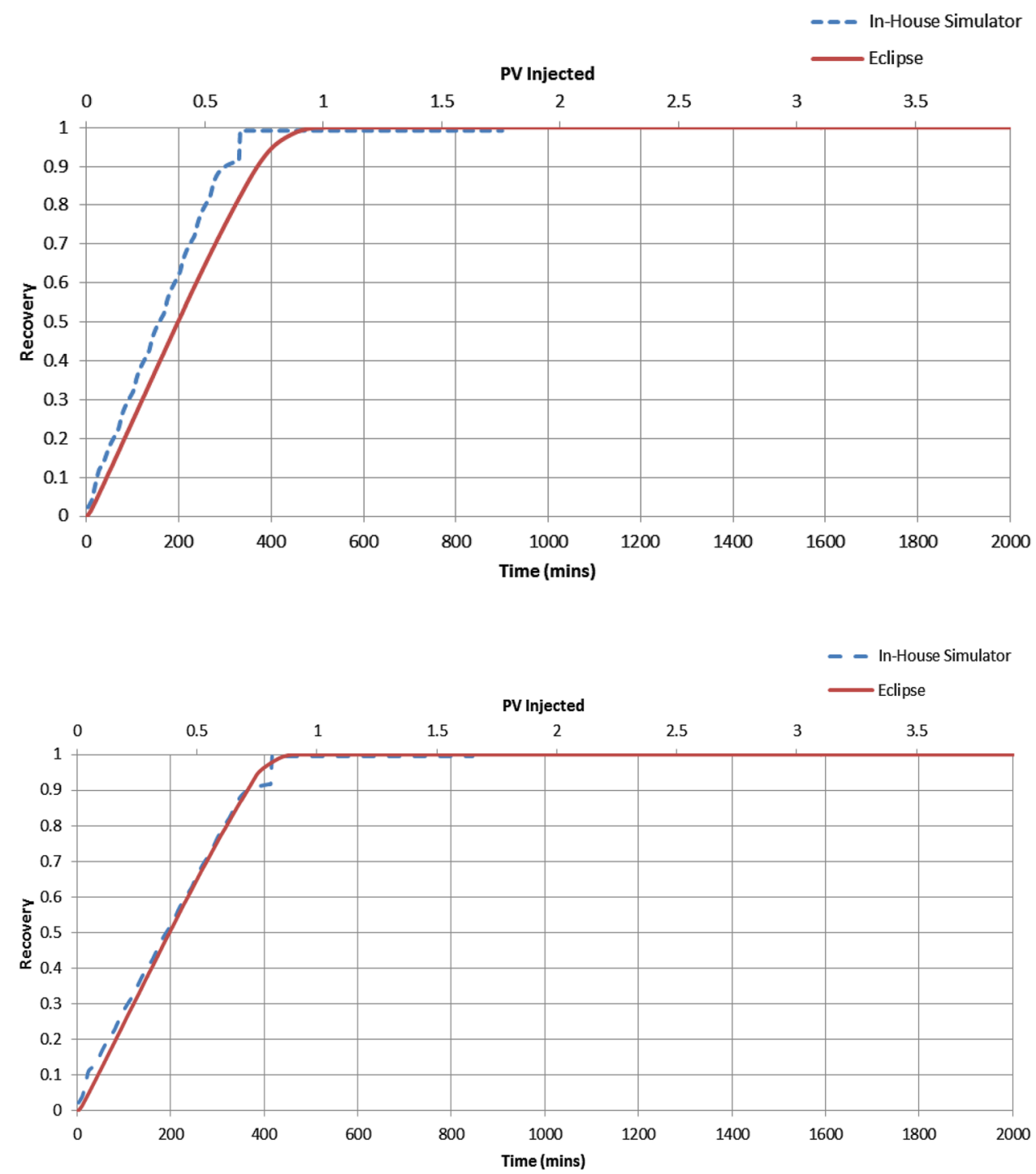

Fig. 13 Recovery versus time/ PV injected, vertical case, Scenario\#3

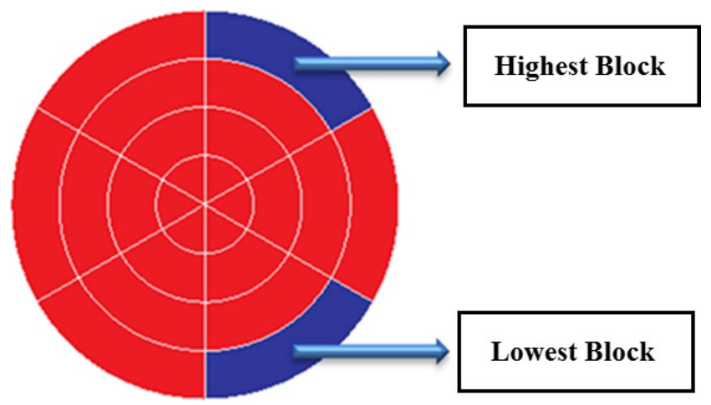

Fig. 14 The highest and the lowest blocks selected to investigate the semi-miscible displacement scenario

Table 5 Gridding parameters for semi-miscible displacement scenario
Table 5 represents gridding parameters of the abovementioned case. The other parameters have been set as the first scenario of the horizontal validation case.

Figures 15 and 16 show variations of pressure, oil and gas saturations in the highest and the lowest blocks of the first layer, respectively.

According to Fig. 15, it can be seen that upon the initiation of the gas injection process, the fluid pressure begins to increase. After a while, the increase in methane fraction in overall composition of the fluid results in formation of gas in this grid block. After about 70 min, gas saturation reaches its maximum $\left(1-S_{w}\right)$.

Meanwhile, Fig. 16 shows that after formation of the gas phase in the lowest block, gravity segregation phenomenon moves the gas to the higher blocks. Consequently, gas saturation in the lowest block decreases to zero again. 
Fig. 15 Pressure $(\mathrm{P})$, gas saturation $\left(\mathrm{S}_{\mathrm{g}}\right)$ and oil saturation $\left(\mathrm{S}_{\mathrm{o}}\right)$ versus time/PV injected in the highest block of the first layer
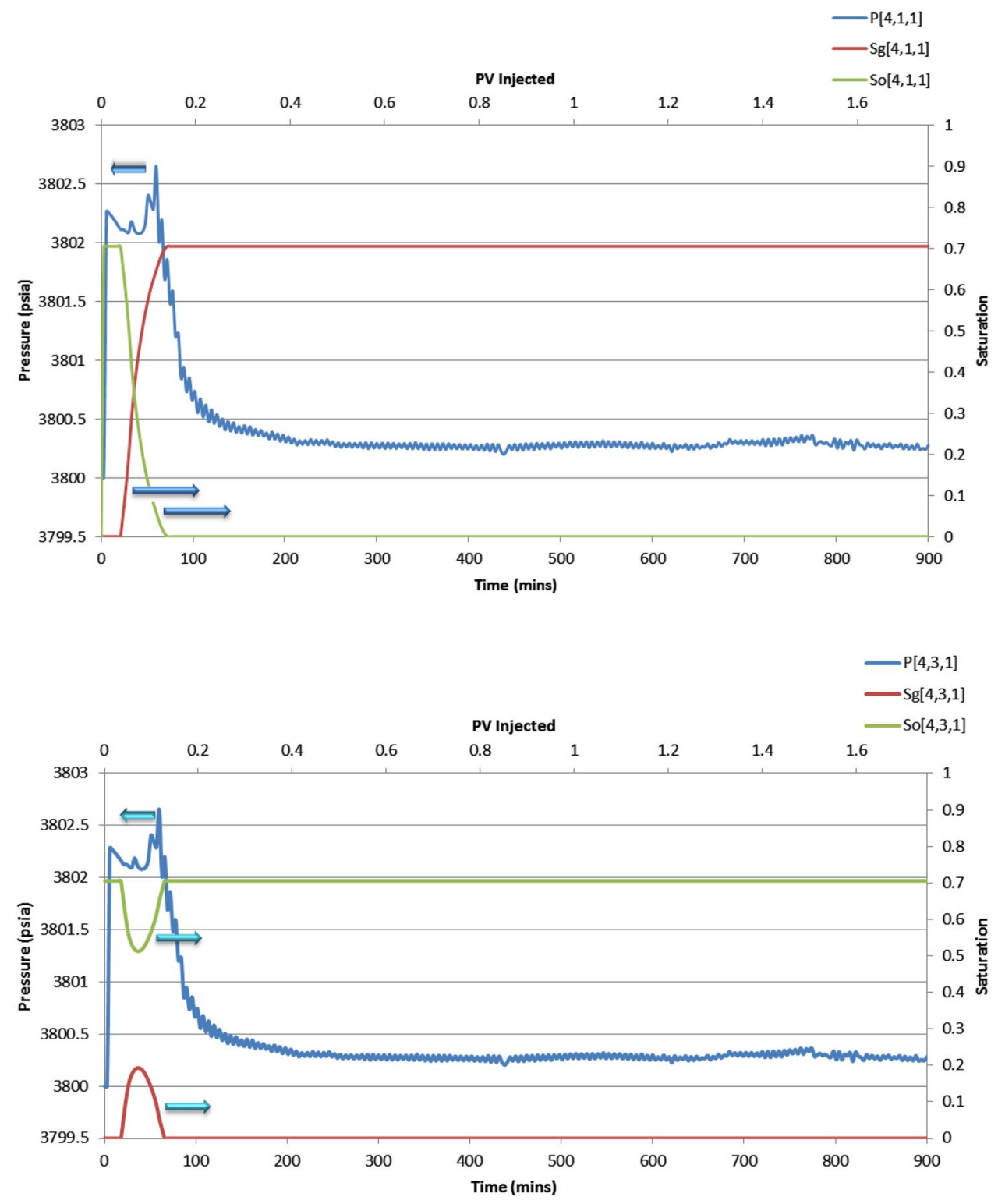

Fig. 16 Pressure $(\mathrm{P})$, gas saturation $\left(\mathrm{S}_{\mathrm{g}}\right)$ and oil saturation $\left(\mathrm{S}_{\mathrm{o}}\right)$ versus time/PV injected in the lowest block of the first layer

\section{Sensitivity analysis}

In this section, the effect of different models and a few parameters are investigated on the results obtained from the developed in-house simulator.

\subsection{Relative permeability models effect}

Figure 17 shows that applying different relative permeability models does not change recovery curve, considerably. It should be mentioned that in these four scenarios, water saturation has been set to irreducible water saturation, so that using Corey's two-phase model make sense.

\subsection{Viscosity models effect}

Figure 18 depicts the effect of three different viscosity models on oil recovery. It is worth mentioning that EF correlation (considering H.R. Motahhari modification in the mixing rules) which has been described as the suitable model for heavy fluids, predicts the lowest recovery amongst the three models. This could be due to the higher estimation of oil viscosity that leads to intensification of gravity segregation phenomena.

\subsection{Grid blocks number effect}

Figure 19 shows the effect of gridblock numbers on oil recovery. Increasing block numbers usually increases precision. But there is a limitation on this parameter which is 
Fig. 17 Effect of relative permeability models on oil recovery

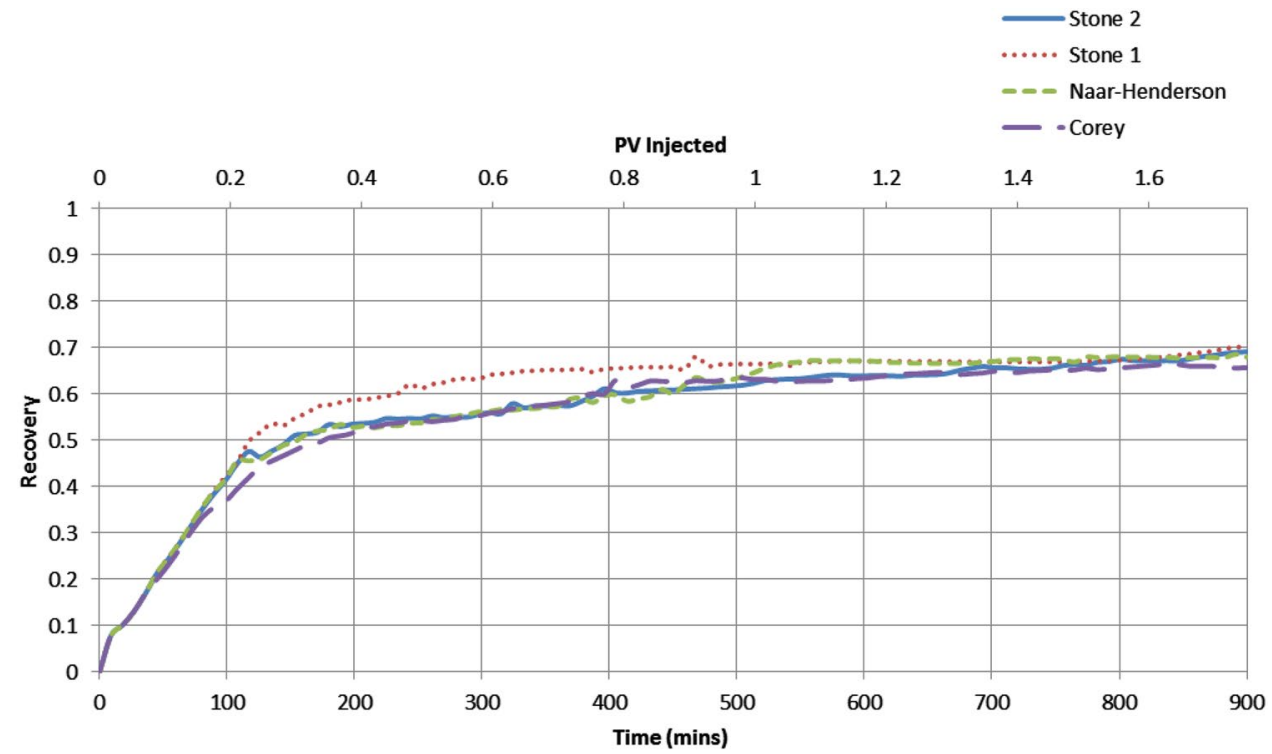

Fig. 18 Effect of viscosity models on recovery

Fig. 19 Effect of gridblock numbers on oil recovery

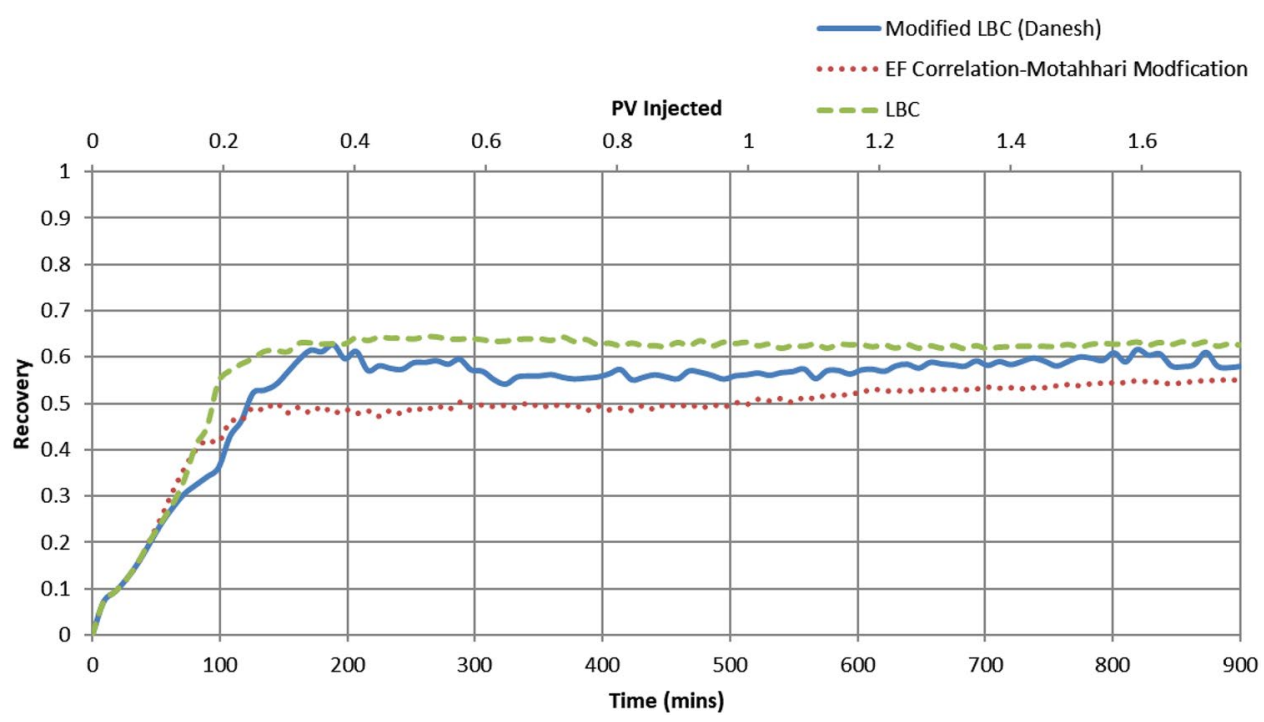

Blocks Number Analysis

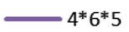

….. $3^{*} 4 * 5$

$---4^{*} 6 * 20$

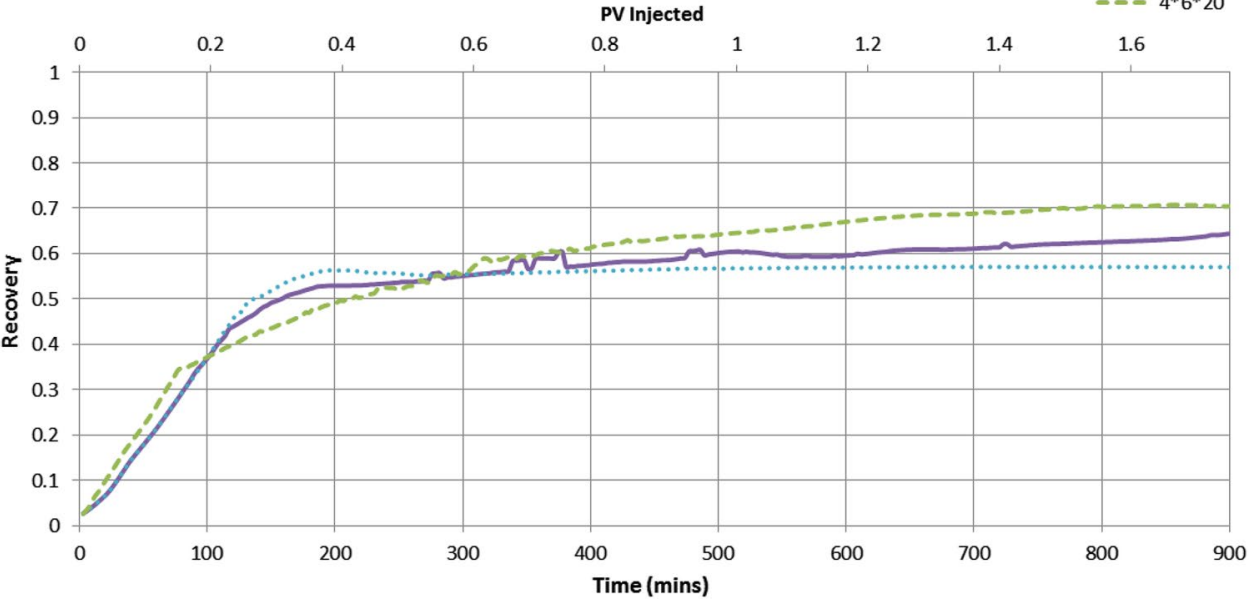


Fig. 20 Effect of timestep on oil recovery

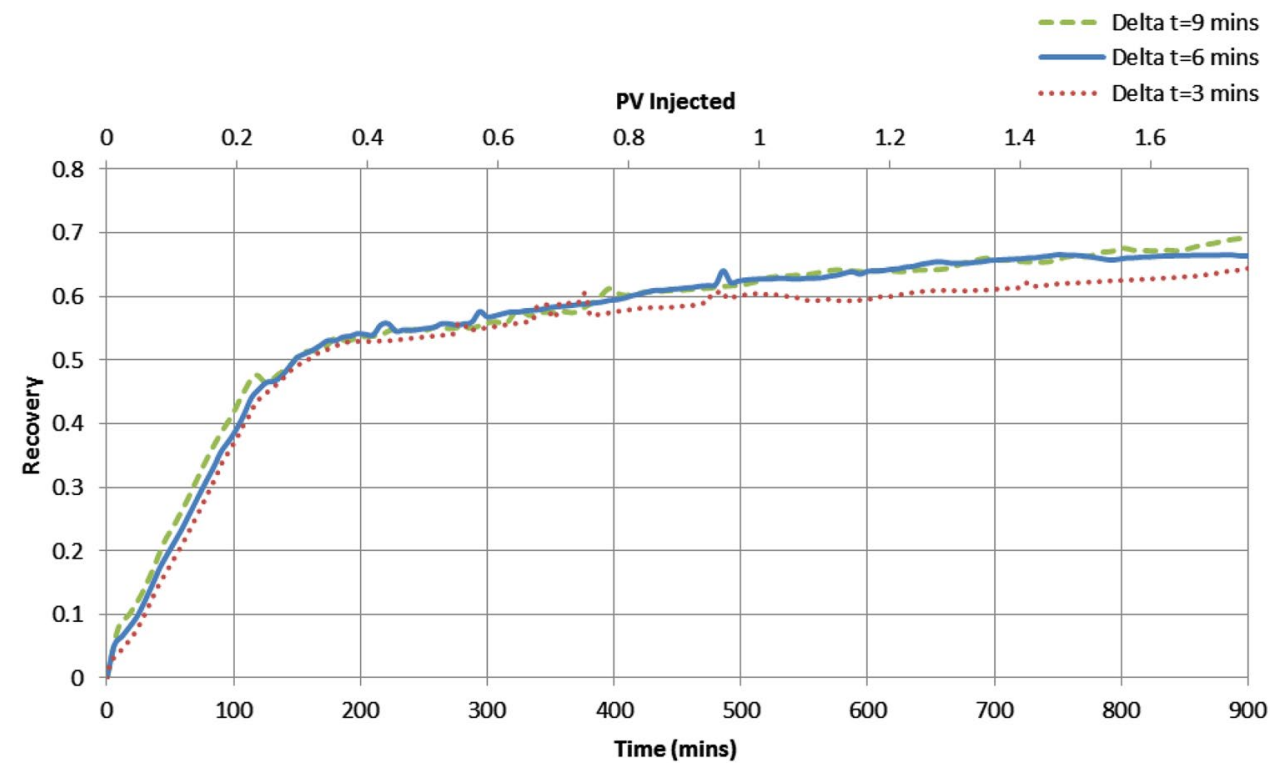

Fig. 21 Effect of core diameter on oil recovery versus time

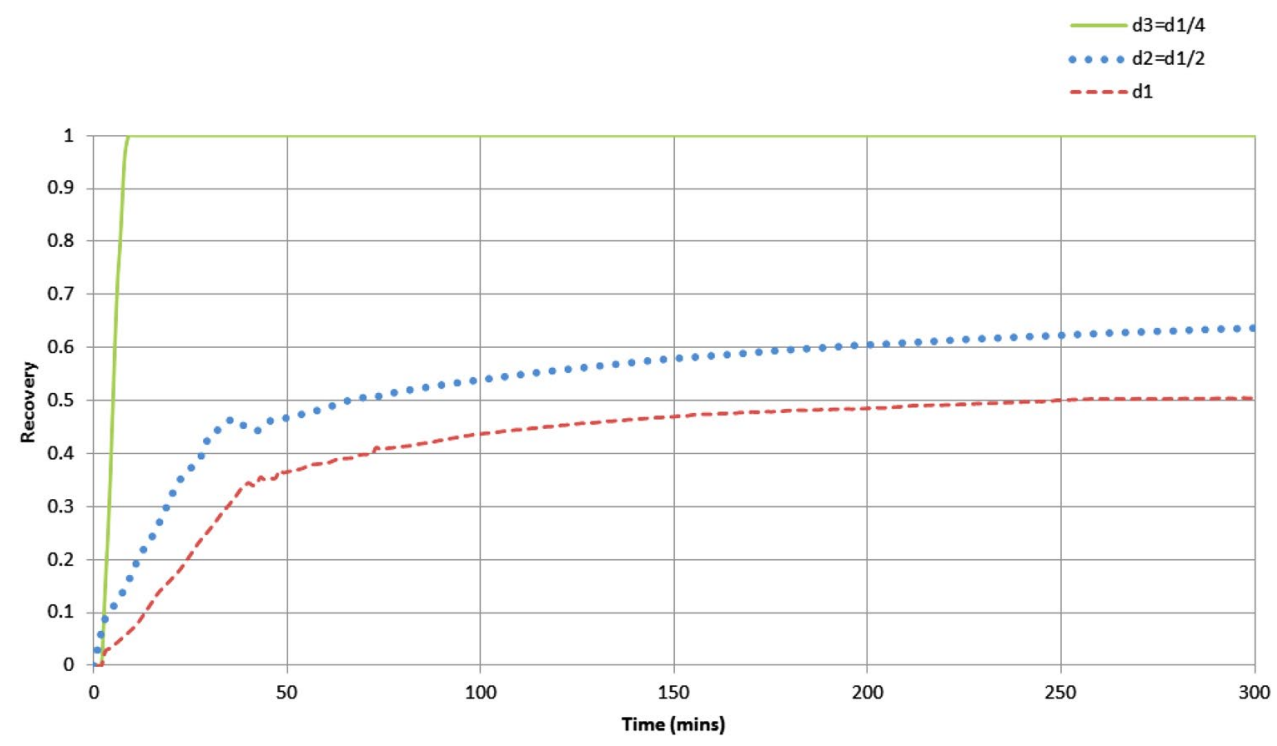

related to time step length that would be described in the next sub-section.

\subsection{Time step effect}

The main limitation of time step and gridblock numbers is that $q \times \Delta t$ should be less than the volume of the movable fluid in each layer. The reason of this limitation is that in this formulation, during each step, mass transfer to just one layer is possible. Figure 20 depicts the effect of time step on oil recovery.

SN Applied Sciences

\subsection{Core diameter effect}

Figures 21 and 22 represent the effect of core diameter on recovery curves versus time and injected pore volumes, respectively. As it is obvious from the figures, decreasing core diameter leads to higher oil recoveries. The reason for this is that as the core diameter decreases, the possibility of gravity segregation effect and early gas breakthrough would also decrease.

\subsection{Core length effect}

Decreasing core length has the same effect on recovery, as decreasing core diameter has (Figs. 23, 24). In each layer, the highest and the lowest gridblocks have the 
Fig. 22 Effect of core diameter on recovery versus $\mathrm{PV}$ injected

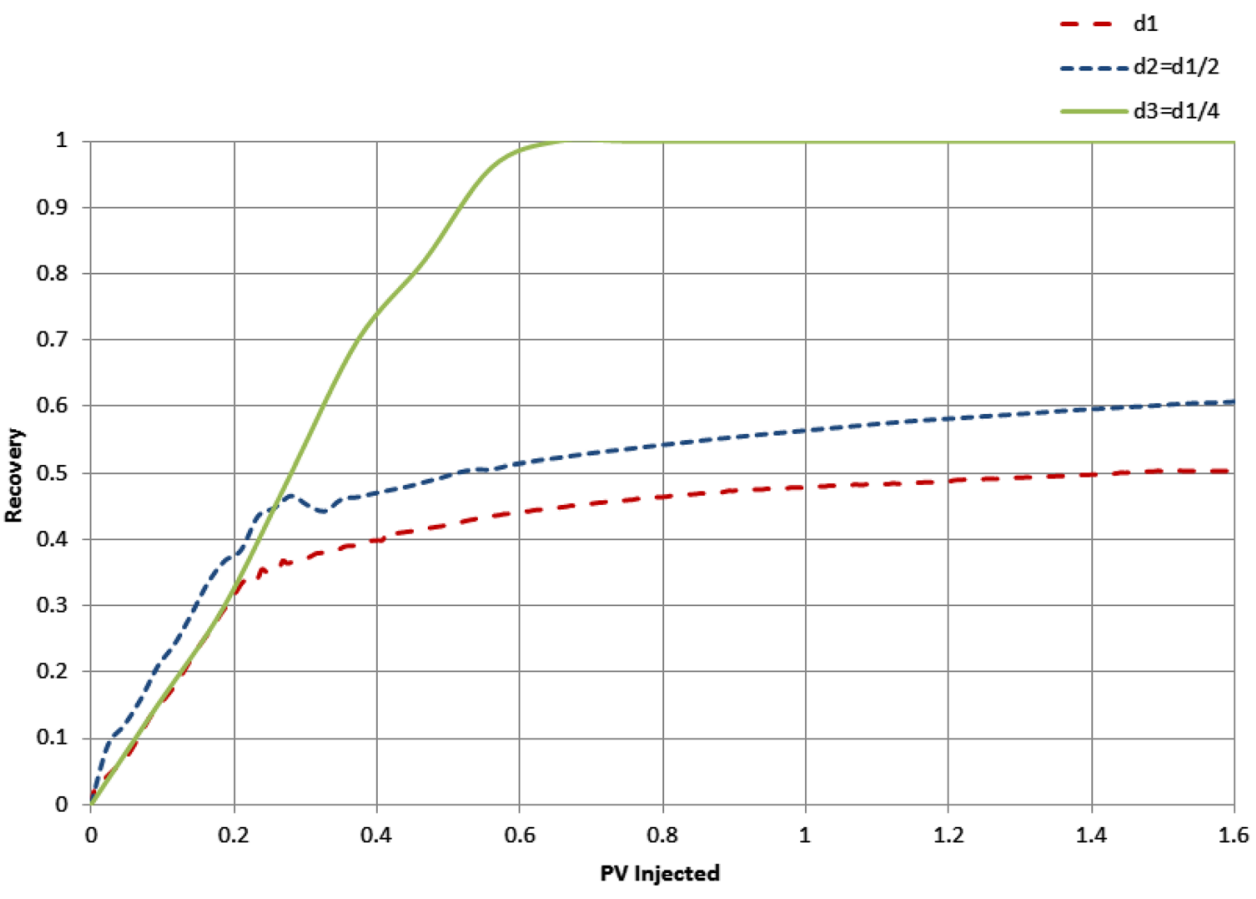

Fig. 23 Effect of core length on oil recovery (vs. time)

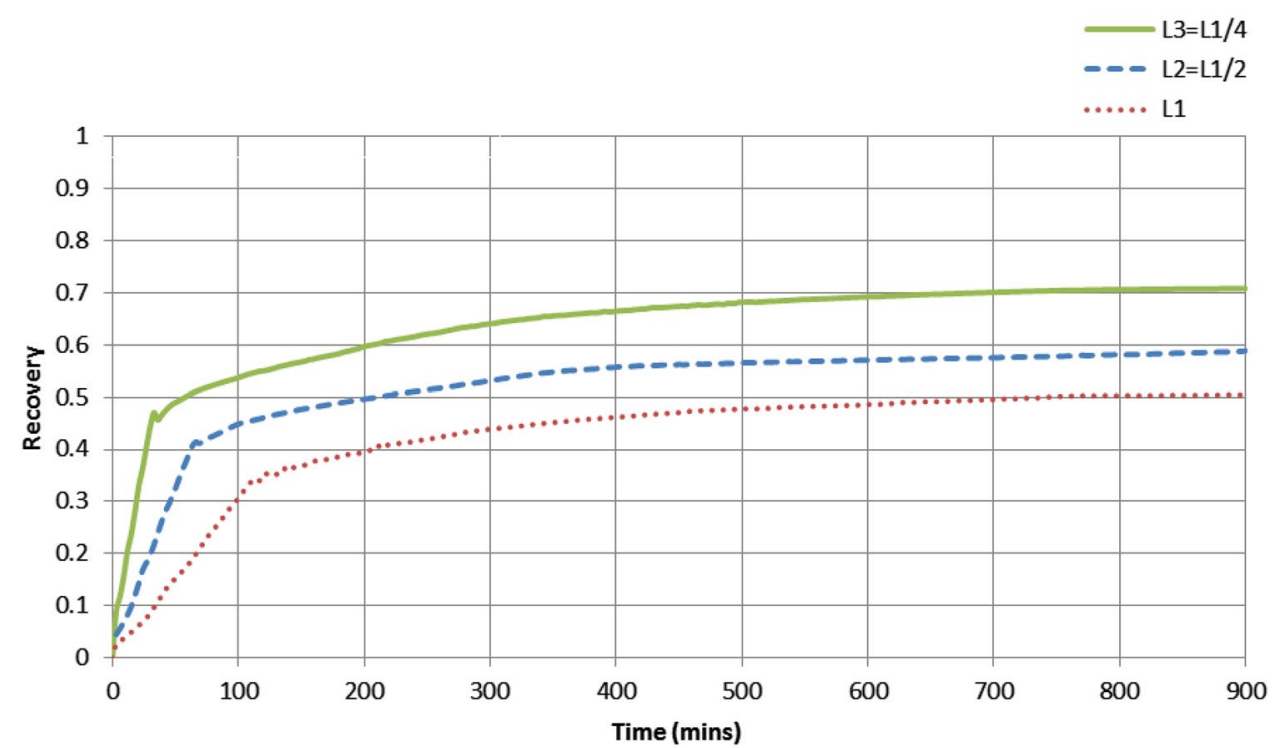

most difference in gas saturation, and gravity segregation begins from the highest gridblocks. In addition, in farther layers from the injection point, this difference increases. The reason for this phenomenon is that after liberation of gas phase, it moves to higher gridblocks, and the gas relative permeability increases by increasing gas saturation. This effect is a kind of fingering which leads to holding up liquid phase in lowest gridblocks. Hence, the lower the core length, the higher oil recovery would be.

\subsection{Pressure effect}

Higher pressure would lead to higher miscibility, and the highest recoveries will be achieved in miscible condition. The effect of pressure on oil recovery is shown in Fig. 25.

\subsection{EoS effect}

In addition to APR EoS, PC-SAFT EoS was also implemented to the developed in-house simulator. In the 
Fig. 24 Effect of core length on oil recovery (vs. PV injected)
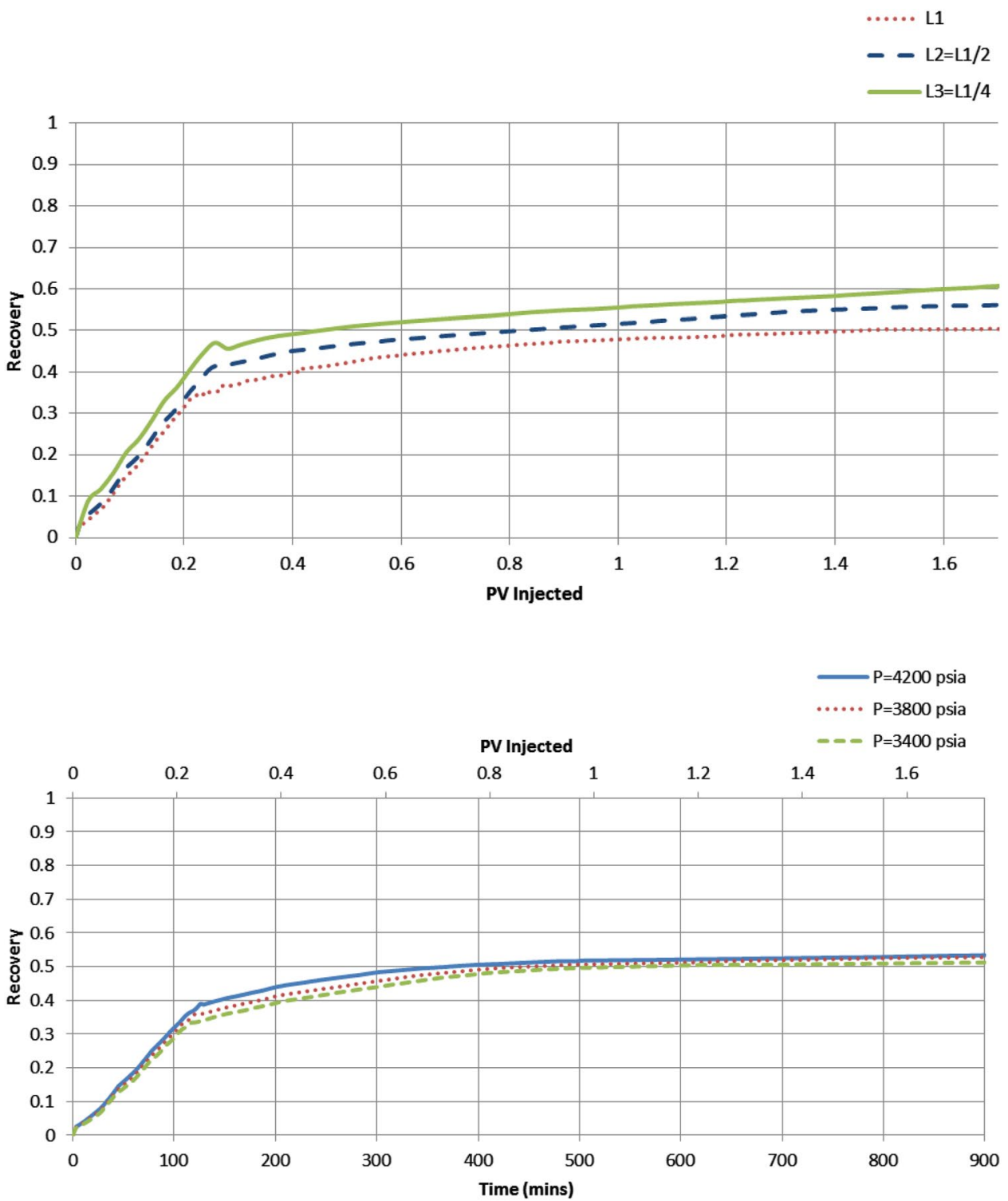

Fig. 25 Effect of pressure on oil recovery
Table 6 Composition of core fluid used to investigate EoS effect

\begin{tabular}{ll}
\hline Component & $\begin{array}{l}\text { Compo- } \\
\text { sition } \\
\text { (mol\%) }\end{array}$ \\
\hline Methane & 10 \\
n-Decane & 10 \\
n-Tetradecane & 10 \\
n-Hexadecane & 10 \\
n-Eicosane & 60 \\
\hline
\end{tabular}

composition has been changed which is given in Table 6. The investigated core fluid in this case is a heavy hydrocarbon and since PC-SAFT EoS accounts for more attraction terms, the lower recovery estimated by PC-SAFT seems to be reasonable (Fig. 26).

\section{Conclusion}

We have presented a fast EoS based compositional model to simulate core-flooding process. The developed in-house simulator has been validated comparing to Eclipse simulator, and several sensitivity analyses have been performed to investigate different parameters and models effects. Eight tuning parameters were defined and optimized for vertical and horizontal cases, the results of which are given in the Tables 7 and 8 . 
Fig. 26 Effect of EoS type on oil recovery

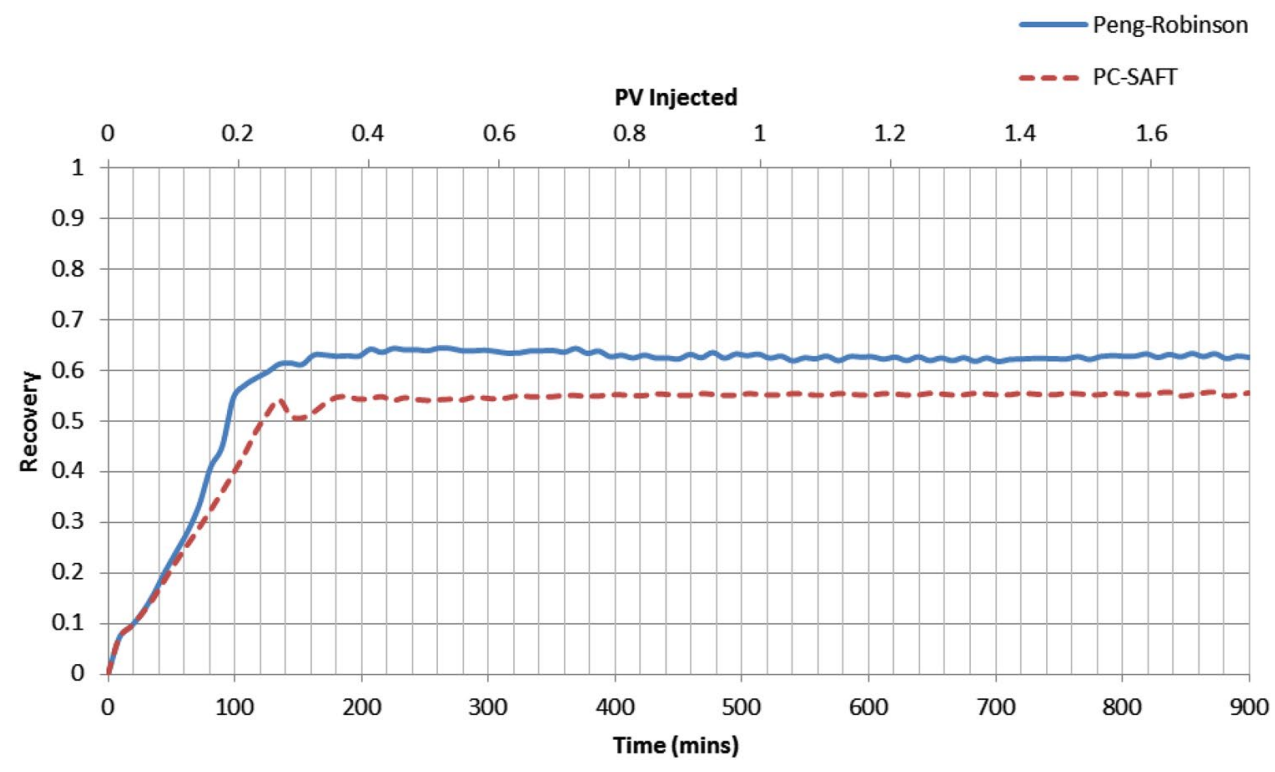

Table 7 Optimized tuning parameters for vertical models

Table 8 Optimized tuning parameters for horizontal models

\begin{tabular}{llll}
\hline$g_{1}$ & $g_{2}$ & $g_{3}$ & $g_{4}$ \\
0 & 0.005 & 0 & 0.995 \\
$l_{1}$ & $l_{2}$ & $l_{3}$ & $l_{4}$ \\
0 & 0.005 & 0 & 0.995 \\
\hline
\end{tabular}

\begin{tabular}{llll}
\hline$g_{1}$ & $g_{2}$ & $g_{3}$ & $g_{4}$ \\
0 & 0.5 & 0.5 & 0 \\
$l_{1}$ & $l_{2}$ & $l_{3}$ & $l_{4}$ \\
0 & 0.5 & 0.5 & 0 \\
\hline
\end{tabular}

Average absolute deviation for calculation of ultimate recovery was $7.68 \%$ and $0 \%$ for the horizontal and vertical scenarios, respectively. The reason for zero AAD of the vertical case is that the assumed core models are homogenous in absolute permeability and porosity. As a result, theoretically the injected gas would be distributed in the core homogenously and all the initial oil in place would be recovered. It must be noted that in reality, inhomogeneity in porosity and permeability can result in fingering phenomena, which decreases ultimate oil recovery.

\section{Compliance with ethical standards}

Conflict of interest The authors declare that they have no conflict of interest.

\section{References}

1. Coats KH (1980) An equation of states computational model. Soc Pet Eng J 20(5):363-376

2. Van Quy N, Simandoux P, Corteville J (1972) A numerical study of diphasic multicomponent flow. AIME Trans Soc Pet Eng J 253:171-184

3. Corteville J, Van Quy N, Simandoux P (1971) A numerical and experimental study of miscible or immiscible fluid flow in porous media with interphase mass transfer, paper SPE 3481 presented at the SPE 46th annual meeting, New Orleans

4. Metcalfe RS, Fussel DD, Shelton JL (1973) A multicell equilibrium separation model for the study of multiple contact miscibility in Rich-gas drives. Trans AIME Soc Pet Eng J 255:147-155

5. Fussel DD, Shelton JL, Griffith JD (1976) Effect of 'Rich' gas composition on multiple-contact miscible displacement-a cell-tocell flash model study. Trans AIME Soc Pet Eng J 261:310-316

6. Fussel DD, Yanosik JL (1978) An iterative sequence for phase equilibria calculations incorporating the Redlich-Kwong Equation of State. Soc Pet Eng J 18:173-182

7. Fussel LT, Fussel DD (1979) An iterative technique for compositional reservoir models. Soc Pet Eng J 19:211-220

8. Nghiem LX, Fong DK, Aziz K (1981) Compositional modeling with an equation of state. SPEJ 21:687-698

9. Young LC, Stephenson RE (1983) A generalized compositional approach for reservoir simulation. SPEJ 23:727-742

10. Branco CM, Rodriguez F (1996) A semi-implicit formulation for compositional reservoir simulation. SPE Adv Technol Ser 4:171-177

11. Wei Y, Chen Z, Satyro M, Dong C, Deng H (2011) Compositional simulation using an Advanced Peng-Robinson Equation of State. In: SPE 141898

12. Zaydullin R, Voskov DV, Tchelepi HA (2013) Nonlinear formulation based on an equation-of-state free method for compositional flow simulation. SPEJ 12:264-273

13. Fleming $G$ (2015) Efficient compositional simulation with locally lumped EoS characterization. In: SPE-175566-MS, SPE reservoir characterisation and simulation conference and exhibition, 14-16 September, Abu Dhabi, UAE

14. Khorsandi S, Li L, Johns RT (2018) A new way of compositional simulation without phase labeling. In: SPE-190269-MS, SPE 
improved oil recovery conference, 14-18 April, Tulsa, Oklahoma, USA

15. Lohrenz J, Bray BG, Clark CR (1964) Calculating viscosities of reservoir fluids from their compositions. Trans AIME JPT 231:1171-1176

16. Al-Syabi Z, Danesh A, Tohidi B, Todd AC, Tehrani DH (2001) A residual viscosity correlation for predicting the viscosity of petroleum reservoir fluids over wide ranges of pressure and temperature. Chem Eng Sci 56(24):6997-7006

17. Satyro MA, Yarranton HW (2010) Expanded fluid-based viscosity correlation for hydrocarbons using an equation of state. Fluid Phase Equilib 298(1):1-11

18. Motahhari HR (2013) Development of viscosity model for petroleum industry applications, PhD Thesis, Chapter Six, University of Calgary
19. Stone HL (1970) Probability model for estimating three-phase relative permeability. Trans AIME JPT 214:249

20. Stone HL (1973) Estimation of three-phase relative permeability and residual oil data. J Cdn Pet Technol 12(4):53

21. Naar J, Henderson JH (1961) An imbibition model-its application to flow behavior and prediction of oil recovery. SPEJ 1:61

22. Naar J, Wygal RJ (1961) Three-phase imbibition relative permeability. SPEJ 1:254

23. Corey AT, Rathjens $\mathrm{CH}$, Henderson JH, Wyllie MRJ (1956) Threephase relative permeability. AIME Trans 207:349-351

Publisher's Note Springer Nature remains neutral with regard to jurisdictional claims in published maps and institutional affiliations. 